\title{
Human Hepatic Flavin-Containing Monooxygenases 1 (FMO1) and 3 (FMO3) Developmental Expression
}

\author{
SEVASTI B. KOUKOURITAKI, PIPPA SIMPSON, CATHERINE K. YEUNG, ALLAN E. RETTIE, \\ RONALD N. HINES \\ Departments of Pediatrics and Pharmacology and Toxicology, Birth Defects Research Center, Medical \\ College of Wisconsin, Milwaukee, Wisconsin 53226, U.S.A. [S.B.K., R.N.H.]; Center for Applied Research \\ and Evaluation, University of Arkansas for Medical Sciences, Little Rock, Arkansas 72202, U.S.A. [P.S.]; \\ and Department of Medicinal Chemistry, University of Washington, Seattle, Washington 98195, U.S.A.
}

[C.K.Y., A.E.R.]

\begin{abstract}
ABST
The flavin-containing monooxygenases (FMOs) are impor-
tant for the metabolism of numerous therapeutics and toxicants.
Six mammalian FMO genes (FMO1-6) have been identified,
each exhibiting developmental and tissue- and species-specific
expression patterns. Previous studies demonstrated that human
hepatic FMO1 is restricted to the fetus whereas FMO3 is the
major adult isoform. These studies failed to describe temporal
expression patterns, the precise timing of the FMO1/FMO3
switch, or potential control mechanisms. To address these ques-
tions, FMO1 and FMO3 were quantified in microsomal fractions
from 240 human liver samples representing ages from 8 wk
gestation to 18 y using Western blotting. FMO1 expression was
highest in the embryo ( $8-15$ wh gestation; $7.8 \pm 5.3$ pmol/mg
protein). Low levels of FMO3 expression also were detectable in
the embryo, but not in the fetus. FMO1 suppression occurred
within 3 d postpartum in a process tightly coupled to birth, but
\end{abstract}
The FMOs (EC 1.14.13.8) are important for the NADPHdependent oxidative metabolism of a wide variety of compounds containing nucleophilic nitrogen-, sulfur-, selenium-, and phosphorous-heteroatoms (1-4). Examples of known substrates of relevance to pediatric therapeutics include the antipsychotic chlorpromazine (5), the antihistaminics promethazine (6) and brompheniramine (7), the $\mathrm{H}_{2}$-receptor antagonists cimetidine (8) and ranitidine (9), and the gastroprokinetic agent itopride (10). However, given the prevalence of nitrogen- and sulfur-heteroatoms in medicinals, this short list is likely a gross underestimate of FMO's contribution to pediatric drug dispo-

Received June 18, 2001; accepted September 26, 2001.

Correspondence: Ronald N. Hines, Ph.D., Medical College of Wisconsin, Department of Pediatrics, Birth Defects Research Center, 8701 Watertown Plank Rd., Milwaukee WI 53226-4801, U.S.A.; e-mail: rhines@mcw.edu

Supported, in part, by National Institutes of Health Grants CA53106 (R.N.H.) and GM43511 (A.E.R.). C.K.Y. was supported by National Institutes of Health Training Grant GM07750. not gestational age. The onset of FMO3 expression was highly variable, with most individuals failing to express this isoform during the neonatal period. FMO3 was detectable in most individuals by $1-2$ y of age and was expressed at intermediate levels until $11 \mathrm{y}(12.7 \pm 8.0 \mathrm{pmol} / \mathrm{mg}$ protein $)$. These data suggest that birth is necessary, but not sufficient for the onset of FMO3 expression. A gender-independent increase in FMO3 expression was observed from 11 to $18 \mathrm{y}$ of age $(26.9 \pm 8.6 \mathrm{pmol} / \mathrm{mg}$ protein). Finally, 2- to 20 -fold interindividual variation in FMO1 and FMO3 protein levels were observed, depending on the age bracket. (Pediatr Res 51: 236-243, 2002)

\section{Abbreviations \\ FMO, flavin-containing monooxygenase TBS, Tris-buffered saline}

sition. Environmental agents of particular concern include several thioether-containing organophosphorous pesticides (11), the carcinogen 2-aminofluorene (12), and the neurotoxicants nicotine (13) and 1-methyl-4-phenyl-1,2,3,6-tetrahydropyridine (MPTP) (14). Finally, a few dietary and/or endogenous FMO substrates have been identified, including trimethylamine, a break-down product of dietary choline (15), cysteamine (16), methionine, and several cysteine-Sconjugates (3).

Unlike the numerous cytochrome P450-dependent monooxygenases, there are only six mammalian FMO enzymes, each encoded by a distinct gene located on the long arm of human chromosome 1 (17, 18). As such, the FMO are considered more versatile with regard to substrate specificity than the cytochrome P450-dependent monooxygenases, a feature partly attributable to the FMO's unique catalytic mechanism (19). FMO species- and tissue-dependent expression has been well documented (20-23) and within a given species and tissue, 
gender- (24) and ontogenic-associated factors (23-25) also may affect FMO expression. Finally, genetic variability within the $F M O$ locus also influences expression (26-29).

Several studies have documented significant changes in the expression of xenobiotic metabolizing enzymes during development (30-33). FMO1 is the major hepatic isoform in most mammals examined to date (4), with the exceptions of the adult human (34) and the adult female mouse (24) where FMO3 is the predominant isoform. FMO1 is expressed at relatively high levels in human fetal liver $(23,25)$ and also represents the major FMO enzyme in the adult human and rabbit intestine and kidney $(22,25)$. Thus, human FMO1 and FMO3 are subject to developmental and tissue-specific regulation, with a temporal switch in the hepatic expression of the two genes occurring some time after birth (23). However, the precise timing of these events and the control mechanisms remain unclear. Such knowledge would provide an improved ability to predict the selective morbidity of numerous toxicants and the efficacy of therapeutic entities, thus advancing our understanding of childhood susceptibility to chemical exposure and our ability to assess risk.

A goal of the current study was to gain a better understanding of the developmental expression pattern for human hepatic FMO1 and FMO3, including the definition of and potential variability in the temporal switch between the two enzymes. A second objective was to determine overall interindividual variation in FMO1 and FMO3 expression as a function of age.

\section{METHODS}

Materials. Polyclonal antibodies raised against human FMO1 and FMO3 peptides and horseradish peroxidaseconjugated goat anti-rabbit IgG were obtained from GENTEST (Woburn, MA, U.S.A.). Protein molecular weight standards (bench mark prestained protein ladder) were from Invitrogen (Carlsbad, CA, U.S.A.). Nitrocellulose membranes and enhanced chemiluminescence Western blotting kits were purchased from Amersham Pharmacia Biotech (Arlington Heights, IL, U.S.A.). The micro bicinchoninic acid protein assay reagent kit was from Pierce Chemical (Rockford, IL, U.S.A.). All other reagents were obtained from common commercial sources at the purest grade available.

Tissue samples. Frozen specimens of human liver were obtained from the Brain and Tissue Bank for Developmental Disorders, University of Baltimore and University of Miami (National Institute of Child Health and Human Development contract N01-HD-8-3284). Additional fetal and embryonic tissues were procured from the Central Laboratory for Human Embryology at the University of Washington. A total of 240 liver samples were obtained representing ages from $8 \mathrm{wk}$ of gestation to $18 \mathrm{y}$ of life. Gender information was provided for 221 samples, 137 being male and 84 female. Other than major diseases and cause of death, no other sample identifiers were available. Samples from individuals with disease processes that potentially would involve liver damage were excluded from the study. Tissue was stored at $-80^{\circ} \mathrm{C}$ until used for the preparation of microsomal suspensions. This study was approved by the Children's Hospital of Wisconsin and the Medical College of Wisconsin Institutional Review Boards.

Preparation of microsomes. Liver microsomes were prepared by differential centrifugation as previously described (35, 36) with some minor modifications. The frozen tissue was allowed to thaw at $4^{\circ} \mathrm{C}$ in homogenizing buffer containing 100 $\mathrm{mM}$ Tris-HCl, $\mathrm{pH}$ 7.4, $250 \mathrm{mM}$ sucrose, $5 \mathrm{mM}$ EDTA, $0.1 \mathrm{mM}$ DTT, and $0.25 \mathrm{mM}$ phenylmethylsulfonyl fluoride. After differential centrifugation, the microsomal pellet was resuspended in $100 \mathrm{mM}$ potassium phosphate $(\mathrm{pH}$ 7.4) containing $1 \mathrm{mM}$ EDTA and $0.15 \mathrm{M}$ potassium chloride and centrifuged again at $104,000 \times g$ for $60 \mathrm{~min}$. The pellet was resuspended in 100 $\mathrm{mM}$ potassium phosphate, $\mathrm{pH} 7.4,1 \mathrm{mM}$ EDTA, and $20 \%$ ( vol $/ \mathrm{vol}$ ) glycerol, and stored in aliquots at $-80^{\circ} \mathrm{C}$. Protein concentrations were determined by the micro bicinchoninic acid protein assay (37) using BSA as a protein standard.

Electrophoresis and immunoblotting. SDS-PAGE, using $10 \%$ resolving gels and a Tris-glycine running buffer, was performed according to the method of Laemmli (38). Fractionation was carried out using the Criterion Precast Gel Electrophoresis System (Bio-Rad, Hercules, CA, U.S.A.), followed by electrophoretic transfer to a nitrocellulose membrane using the Criterion Blotter (Bio-Rad) (39). Twenty micrograms of microsomal protein were used for each sample. Nonspecific binding sites were blocked by overnight incubation at $4^{\circ} \mathrm{C}$ with $5 \%$ nonfat dry milk in Tris-buffered saline (TBS; $25 \mathrm{mM}$ Tris, $\mathrm{pH} 7.5,150 \mathrm{mM}$ sodium chloride). The blots were then incubated for $1 \mathrm{~h}$ at room temperature with FMO1 or FMO3 primary antibody diluted 1:5000 in TBS containing 0.5\% nonfat dry milk. After extensive washing with several changes of TBS supplemented with $0.1 \%$ Tween-20, the blots were incubated for $1 \mathrm{~h}$ at room temperature with horseradishconjugated goat anti-rabbit IgG diluted 1:10,000 in TBS containing $0.5 \%$ nonfat dry milk. Blots were then washed with several changes of TBS supplemented with $0.1 \%$ Tween- 20 and processed for detection by enhanced chemiluminescence according to the manufacturer's instructions. The luminescence produced was detected by exposure of Fuji Super RX film (Fisher Scientific, Pittsburgh, PA, U.S.A.) and after digitizing the image using a Hewlett Packard 6300C scanner (Boise, ID, U.S.A.), the integrated OD of immunoreactive protein bands was determined using a Kodak DC120 digital camera and Digital Science 1D V 3.0 software (New Haven, CT, U.S.A.). Human FMO1 and FMO3 were expressed in a baculovirus vector expression system and insect cell membranes prepared as described previously (25). To quantify the amount of FMO in the preparations, the flavin adenine dinucleotide content of the membrane preparations was determined by HPLC (15). For a standard curve, membrane protein preparations representing 25, 50, 100, 250, and $500 \mathrm{fmol}$ of FMO1 and FMO3 were included on each blot. The FMO1- and FMO3-specific content of the patient samples was determined by linear regression based on this standard curve (GraphPad Instat version 3.00, GraphPad Software, San Diego, CA, U.S.A.). The sensitivity limit was $0.2 \mathrm{fmol}$ of FMO1 or FMO3. In all blots, bands corresponding to the protein of interest (FMO1 or FMO3) were identified by reference to the baculo- 
virus-expressed FMO1 and FMO3 and molecular weight standards.

Data analysis. Data breakpoints giving the maximum variance between groups and the least deviance within groups were determined by regression tree analysis using S-Plus 2000, a statistical package from Insightful Corp. (Seattle, WA, U.S.A.). Samples with specific contents falling at least 1.5 times outside the 25 th to 75 th percentile values were considered outliers and were not included in the analysis. The significance of differences between groups was confirmed by a Kruskal-Wallis nonparametric analysis of variance with MannWhitney $U$ tests used for pair-wise comparisons. Multiple comparisons were corrected for using a Bonferroni adjustment (the $p$ value multiplied by 3). A $p$ value $<0.05$ was accepted as significant.

\section{RESULTS}

Developmental expression pattern for FMO1 and FMO3. Previous studies provided evidence for FMO1 and FMO3 differential expression in human liver during development (40, $23,25)$. However, none of these reports addressed the temporal expression pattern of these enzymes, the precise timing of the FMO1/FMO3 switch, or potential control mechanisms. In the present study, the developmental expression pattern of human hepatic FMO1 and FMO3 was determined by SDS-PAGE and Western blot analysis of microsomal protein prepared from a bank of 240 human liver samples. Western blotting with antibodies to FMO1 or FMO3 revealed immunoreactive bands with apparent molecular masses near $60 \mathrm{kD}$, corresponding to full-length FMO1 or FMO3, respectively. Figure 1, $A$ and $B$, depicts representative blots with human hepatic microsomes of different ages. No cross-reactivity was observed between the respective antibodies and antigens, even at the highest protein levels used $(500 \mathrm{fmol})$. In agreement with previous studies, FMO1 expression was present in embryonic and fetal liver (Fig. 1A) but not in any of the postnatal liver samples. In contrast, FMO3 expression was not detectable in fetal liver samples, but was present in postnatal samples (Fig. 1B). The coefficient of determination $\left(r^{2}\right)$ values for the standard curves ranged from 0.960 to 0.998 (median $=0.990$ ) and typical coefficients of variation for independent experiments were 5.6 for FMO1 $(n=5)$ and 4.6 for FMO3 $(n=6)$.

The overall developmental-specific expression patterns for FMO1 and FMO3 are shown in Figure 2, $A$ and $B$. Although there was significant interindividual variation, the highest level of FMO1 expression was observed at the earliest gestational ages, i.e. less than $15 \mathrm{wk}$ (Fig. 2A). After this period, there was a decline in FMO1 expression up to $40 \mathrm{wk}$ (term). In contrast to earlier reports $(40,23)$, low levels of FMO3 expression were detected in 7 of 38 embryonic samples between 8 and $15 \mathrm{wk}$ gestation $(1.4 \pm 0.9 \mathrm{pmol} / \mathrm{mg}$ microsomal protein). No FMO3 expression was observed between 15 and $40 \mathrm{wk}$ gestation. The FMO1/FMO3 developmental expression pattern was quite different after birth. As shown in Figure 2B, there was a dramatic decline in FMO1 expression within the first few days of life. Although variable, the onset of FMO3 expression was generally observed during the first year of life followed by moderate
A

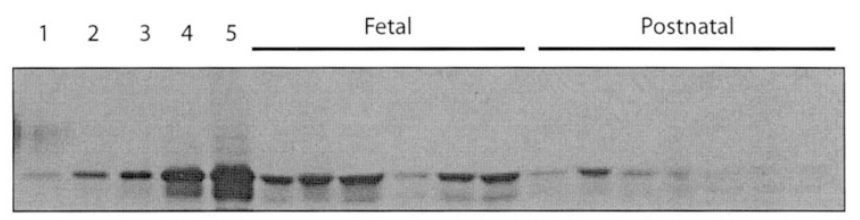

B
$\begin{array}{llll}1 & 2 & 3 & 4\end{array}$
5 Fetal \& Neonatal
Postneonatal

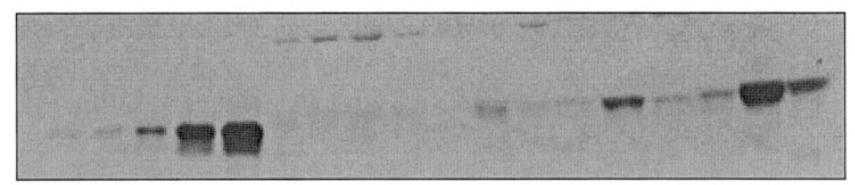

Figure 1. Western blot analysis of FMO1 and FMO3 expression in human liver microsomes. Twenty micrograms of microsomal protein were fractionated by SDS-PAGE, electrophoretically transferred to nitrocellulose membranes, and the blots probed with polyclonal antibodies against human FMO1 $(A)$ or FMO3 $(B)$, followed by secondary antibody and detection using enhanced chemiluminescence with 1- to 5-min exposures. Lane 1, $25 \mathrm{fmol}$; lane 2, $50 \mathrm{fmol}$; lane 3, $100 \mathrm{fmol}$; lane 4, $250 \mathrm{fmol}$; lane 5, $500 \mathrm{fmol}$ of FMO1 $(A)$ or FMO3 $(B)$ standards. Remaining lanes on each blot represent $20 \mu \mathrm{g}$ of microsomal protein from a selected group of liver samples.

expression up to $11 \mathrm{y}$ of age. Significant interindividual variability also was observed during this period. A second phase of FMO3 expression was observed from puberty to adult, where FMO3 expression increased to a maximum level of approximately $40 \mathrm{pmol} / \mathrm{mg}$ microsomal protein. No correlation was observed between FMO1- or FMO3-specific content and the postmortem interval, i.e. the time between death and the freezing of liver tissue (data not shown).

Definition of the FMO1/FMO3 temporal switch. To better elucidate the precise timing of the hepatic FMO1/FMO3 isoform switch, an expanded plot of FMO1 and FMO3 expression during the neonatal period (birth to $30 \mathrm{~d}$ ) and the first year of life was examined (Fig. 3). FMO1 expression was low, but detectable in most samples within the first $3 \mathrm{~d}$ of life, but then was extinguished in all but a few samples. In contrast, the onset of FMO3 expression was highly variable during the neonatal period and, when present, was low relative to expression levels observed at later ages. A significant increase in expression was observed between the neonatal period and $1 \mathrm{y}$ of age. As a first approach to determining the mechanism(s) regulating the FMO1/FMO3 isoform switch, an analysis of specific FMO content as a function of gestational and postnatal age was performed using liver samples from premature infants that lived for a defined period of time after birth (Fig. 4). From this analysis, FMO1 expression clearly was extinguished within the first few days of life, irrespective of gestational age, consistent with the suppression of FMO1 expression being tightly linked to the birth process, but not maturity. A direct linkage of birth to the onset of FMO3 expression was less clear. With the exception of 4 outliers from a total of 15 samples, FMO3 
expression was nondetectable during the first $3 \mathrm{~d}$ of life, irrespective of gestational age. From Figure $2 A$, no FMO3 expression was detectable in any of the late fetal samples that did not survive for any defined period after birth. Low but detectable FMO3 expression was observed in 4 of 13 samples between $4 \mathrm{~d}$ and 30 wk postnatal age, irrespective of gestational age at the time of birth. Together with the results presented in Figure 3, these data are consistent with birth being necessary but not sufficient for the onset of FMO3 expression.

Interindividual and temporal variation in FMO1 and FMO3 expression. To better summarize the different phases of FMO1 and FMO3 developmental expression, as well as quantify the interindividual variability in expression, the data presented in Figures 2-4 were re-analyzed using regression trees. This method determined data breakpoints that would provide for maximal variation in data between groups and minimal deviation within a group. Results of this analysis are shown in Figure 5. From this analysis of the data, FMO1 expression divides into three phases approximately matching the trimesters of development. Maximum FMO expression was observed in samples $<15 \mathrm{wk}$ gestation $(7.8 \pm 5.3 \mathrm{pmol} / \mathrm{mg}$ microsomal protein). During the second trimester (15 wk to 6 mo), mean

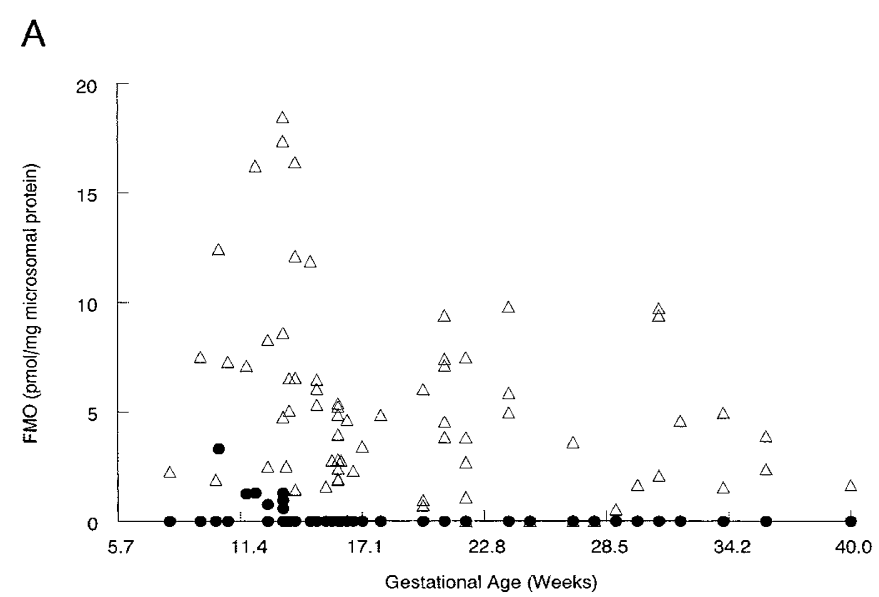

B

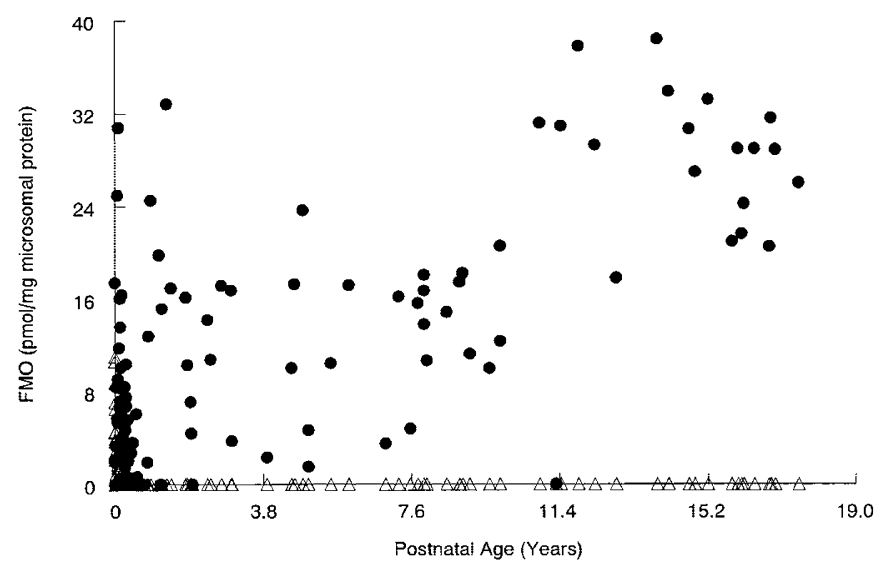

Figure 2. Developmental-specific expression pattern of FMO1 and FMO3. (A) A scatter plot analysis of FMO1- (open triangle) and FMO3- (filled circle) specific content as a function of gestational age (weeks) is depicted. (B) A scatter plot analysis of FMO1 (open triangle) and FMO3 (filled circle) specific content as a function of postnatal age (years) is depicted.

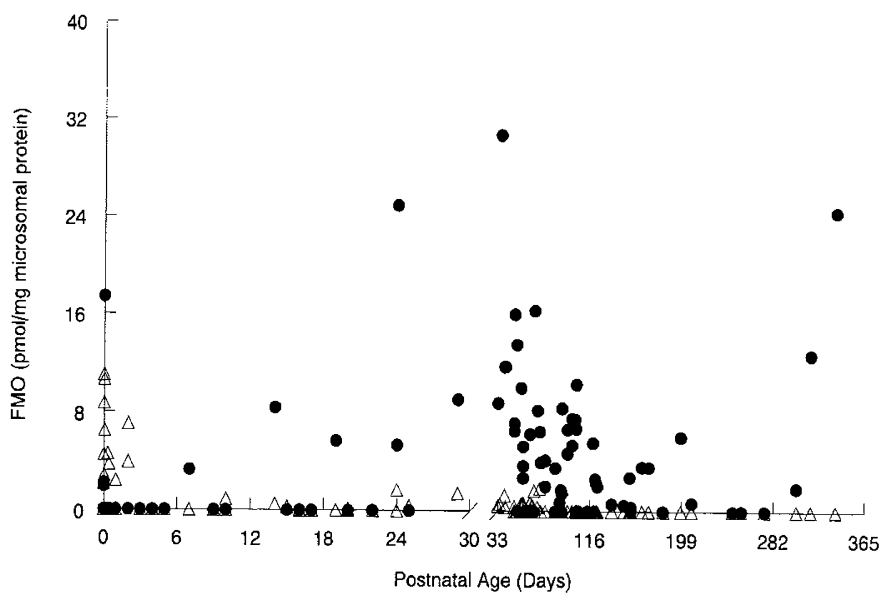

Figure 3. Expression pattern of FMO1 and FMO3 in the first year of life. An expanded plot of FMO1- (open triangle) and FMO3- (filled circle) specific content as a function of age within the first year is shown. Note the split $x$ axis to better illustrate the expression pattern during the neonatal period.

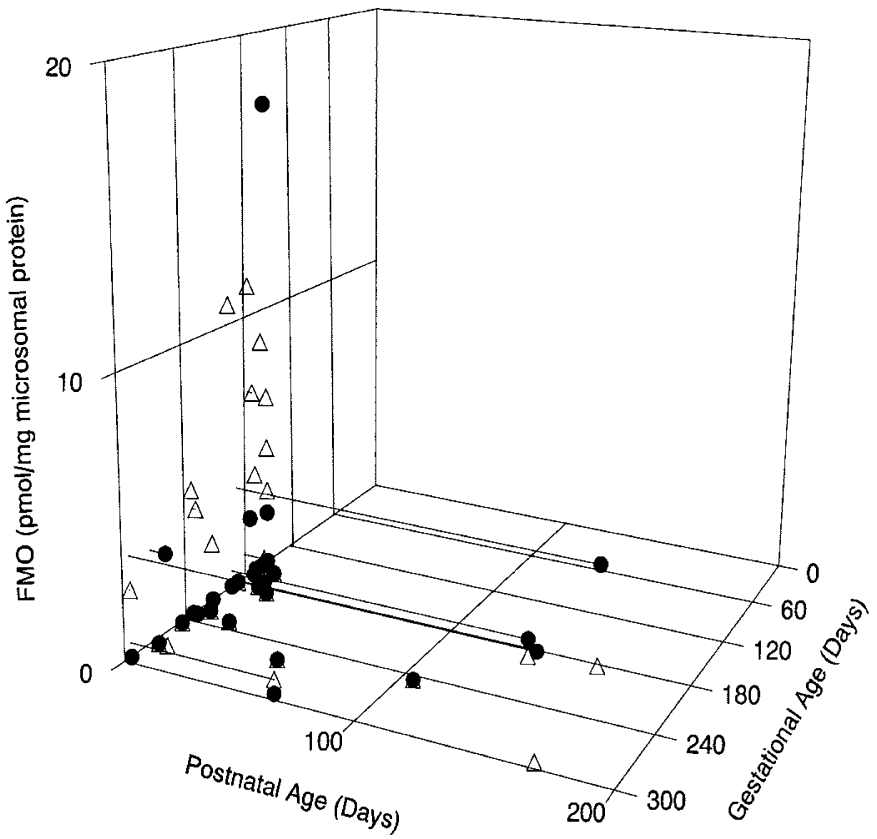

Figure 4. Regulation of FMO1 suppression and onset of FMO3 expression by maturity and/or birth. FMO1 (open triangle) and FMO3 (filled circle) specific content in samples from premature patients who lived for defined periods of time after birth were plotted as a function of both gestational age (days) at time of birth and postnatal age (days) at time of death.

expression levels decreased by approximately $50 \%(3.8 \pm 2.6$ $\mathrm{pmol} / \mathrm{mg}$ microsomal protein) and again by a further $50 \%(2.1$ $\pm 1.8 \mathrm{pmol} / \mathrm{mg}$ microsomal protein) in the third trimester. FMO1 expression was essentially nondetectable after $3 \mathrm{~d}$ postpartum. Interindividual variation in FMO1 expression during the prenatal period was 10 - to 20 -fold. FMO3 expression was only observed in a small number of samples and only during the embryonic period at $<15 \mathrm{wk}$ gestation (see Fig. $2 A$ ). After 2-3 d postpartum, overall FMO expression (FMO1 plus FMO3) was absent in the majority of samples and remained low to nondetectable for the first $3 \mathrm{wk}$ of life. In those with detectable protein, FMO3 predominated with expression levels that were $<5 \%$ of those observed in the adult $(1.1 \pm 3.3$ 
A

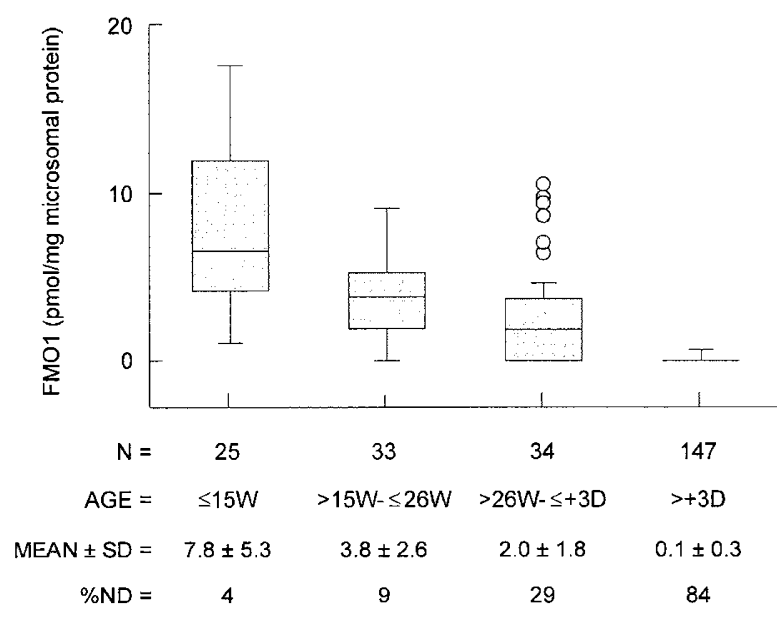

B

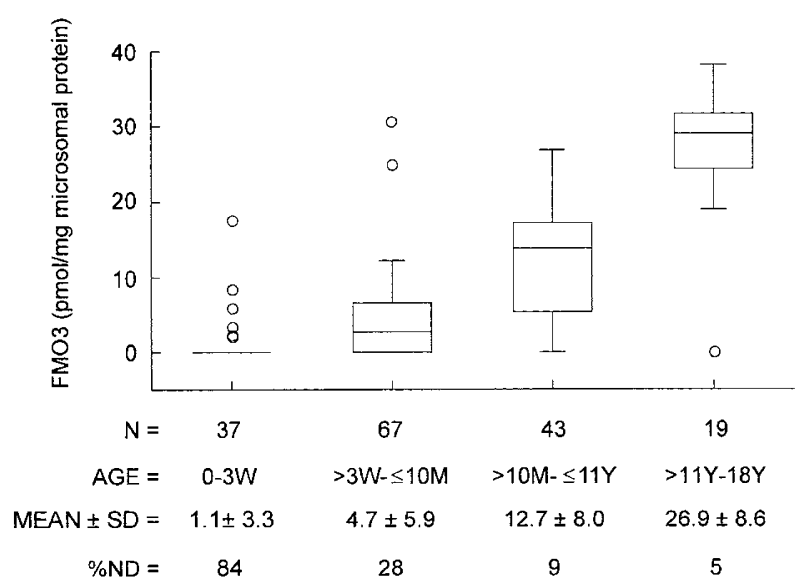

Figure 5. Determination of the interindividual variability in FMO1 and FMO3 developmental expression. A box and whisker plot analysis of the complete data set of FMO1- $(A)$ and FMO3- $(B)$ specific content is depicted. Optimal age brackets were determined using regression trees (see "Materials and Methods"). The boxes represent the 25th to 75th percentiles and the horizontal bar the median of the data. The vertical bars represent 5th to 95th percentiles of the data. These analyses excluded outliers, defined as having specific contents outside 1.5 times the 25 th to 75 th percentiles. Data points representing these outliers are depicted. The sample size within each bracket $(N)$, age ranges ( $W$, weeks; $D$, days; $M$, months; $Y$, years; + indicates postnatal age in $A$ ), FMO-specific content (mean $\pm \mathrm{SD}, \mathrm{pmol} / \mathrm{mg}$ microsomal protein), and the fraction of samples with nondetectable protein $(\% N D)$ for each age bracket also are shown. With the exception of the 0 - to 3 -wk age bracket for FMO3, the calculations of mean $\pm \mathrm{SD}$ also excluded outliers.

$\mathrm{pmol} / \mathrm{mg}$ microsomal protein). The regression tree analysis suggests that the postneonatal FMO3 expression can be divided into three phases. Between $3 \mathrm{wk}$ and 10 mo, mean FMO3 expression increased 5 -fold $(4.7 \pm 5.9 \mathrm{pmol} / \mathrm{mg}$ microsomal protein) and then another approximate 3 -fold between $10 \mathrm{mo}$ and $11 \mathrm{y}(12.7 \pm 8.0 \mathrm{pmol} / \mathrm{mg}$ microsomal protein). Between 11 and $18 \mathrm{y}$ of life, there was a third significant increase in mean expression levels (2-fold increase to $26.9 \pm 8.6 \mathrm{pmol} / \mathrm{mg}$ microsomal protein). Pair-wise comparisons of FMO1- and FMO3-specific content between each of the age brackets demonstrated significant differences between all age brackets $(p<$ $0.05)$.
Gender-selective FMO expression. Given the previous studies indicating the ability of the sex steroids and/or gender to modulate FMO expression in animal models $(24,41-45)$ and the evident increase in FMO3 expression at puberty in the current study, the potential role of gender in regulating postnatal human hepatic FMO expression was examined. When gender was entered as a possible categorical variable in the regression tree analysis, it failed to enter into the model (data not shown). Thus, in the human, gender-associated factors do not appear important in either the pre- or postpuberty phases of FMO3 expression.

\section{DISCUSSION}

Previous studies provided evidence for FMO isoform switching in the human from FMO1 in fetal liver to FMO3 in the adult $(23,25)$. However, the precise timing of this event and specific control mechanism(s) remained unknown. Further, these previous studies were limited in scope to short windows of time during development and also by relatively small sample sizes. In the present study, an effort was made to comprehensively characterize the developmental expression pattern for human hepatic FMO1 and FMO3, better defining the temporal switch between the two enzymes and determining interindividual variation in expression. Western blot analysis of 240 human liver microsomal samples, ranging from 8 wk gestation to $18 \mathrm{y}$ of life, confirmed that FMO1 is the major fetal isoform whereas FMO3 is the major adult isoform. The highest level of FMO1 expression was observed in embryonic samples at 8 to $15 \mathrm{wk}$ gestation. In contrast to earlier reports $(40,23)$, low levels of FMO3 expression were detectable in some embryonic samples, but not in fetal samples. This discrepancy may be due to the low sample numbers used in previous studies, uncertainty about the age of these samples, and/or the sensitivity of the assay used. The results reported herein also suggest that FMO1 suppression occurs within the first few days of life in a process that is tightly coupled to birth, but not gestational age. However, FMO1 suppression is not directly linked to the onset of FMO3 expression (linear regression correlating FMO1- and FMO3-specific content during first year of life, $r^{2}=0.009$ ) (data not shown). The latter is highly variable, with most individuals failing to express FMO3 during the neonatal period (first $30 \mathrm{~d}$ of life). When neonatal expression was detectable, it was 5 to $10 \%$ of adult levels, although one individual exhibited FMO3 protein levels approaching those seen in the adult. Thus, with rare exception, hepatic FMO expression is absent or low during the neonatal period in the human. This conclusion assumes the absence of other FMO isoforms, however, previous studies have suggested that FMO2, FMO4, and FMO5 are not expressed, or are expressed at very low levels in the human liver (46). Very little is known regarding FMO6 and, thus, the contribution of this enzyme remains a potential limitation to the interpretation of these data. FMO3 expression is detectable in most individuals by $1-2 \mathrm{y}$ of age and is expressed at intermediate levels until approximately $11 \mathrm{y}$. Taken together with the absence of detectable fetal FMO3 protein, these results suggest that birth is necessary but not sufficient for the initial onset of FMO3 expression. A further increase in FMO3 
expression is observed from 10 to $18 \mathrm{y}$ of age, reaching a maximum level of approximately $40 \mathrm{pmol} / \mathrm{mg}$ microsomal protein in the current sample population. This level of FMO3 expression is not as high as the maximum reported by Overby et al. (47), but does fall within the range of values reported by these investigators $(5-112 \mathrm{pmol} / \mathrm{mg}$ microsomal protein). It is possible that maximum adult levels have not been reached by the highest age represented in the current study, i.e. $18 \mathrm{y}$. Importantly, neither the onset of FMO3 expression nor the increase in expression at puberty appears linked to gender. Finally, FMO1 and FMO3 expression varies 2- to 20-fold among individuals, depending on the age bracket.

A few studies have reported FMO developmental expression patterns in experimental animal models, although most limited their studies to late fetal stages and postnatal development. In the rabbit lung, FMO2 expression was observed in the fetus and during the neonatal period, in some instances approaching levels observed in the adult animal (48). However, in the liver, FMO1 is a major isoform observed in the rabbit and most other mammalian species, and as such, it is difficult to extrapolate results from these models to the human. A possible exception is the mouse. Cherrington et al. (24) demonstrated the presence of substantial FMO1 and FMO5 expression in CD-1 mouse liver as early as $15 \mathrm{~d}$ gestation. However, FMO3 was nondetectable during any prenatal period. FMO3 was detectable in the CD-1 mouse liver by 2 wk postpartum. However, in contrast to what is observed in the human, hepatic FMO1 continues to be expressed postpartum in the mouse. Also in contrast to the human, substantial gender differences in hepatic FMO expression become apparent in the adult rodent models. Thus, FMO3 expression is suppressed in the adult male, but not female mouse and FMO1 expression also is significantly higher in the female versus male. FMO3 expression in the adult rat was gender-independent. Thus, the similarities between the animal models and the human appear restricted to the expression of FMO1 in the fetal liver and the onset of FMO3 expression shortly after birth. The absence of FMO1 suppression and the overall gender differences in FMO expression again cause one to question the validity of extrapolating data from these animal models to the human.

The observed FMO1 and FMO3 developmental expression pattern is somewhat reminiscent of the pattern observed for two human CYP3A isoforms. Similar to what is observed in the present study, CYP3A7, but not CYP3A4, is expressed at easily detectable levels in human embryonic hepatic tissues at 7-9 wk of gestation (49), as well as in later fetal stages of development (50). Maximal CYP3A7 activity is observed within the first week of life, but then slowly declines to nondetectable levels in the adult. In contrast, CYP3A4 expression is low or nondetectable in the fetal period, but is activated during the first week of life irrespective of gestational age. By $1 \mathrm{y}$, CYP3A4 expression is at a level approximately $50 \%$ of that seen in the adult (50). Although the temporal switch in CYP3A expression shows some similarity to that observed for FMO, important differences also are noted. First, in contrast to CYP3A4, FMO3 expression is nondetectable in the fetal liver. Second and perhaps more importantly, the suppression of CYP3A7 and activation of CYP3A4 appear directly linked such that overall CYP3A expression is essentially constant (50). In contrast, the suppression of FMO1 and the activation of FMO3 do not appear linked. FMO1 suppression occurs within the first 2 to $3 \mathrm{~d}$ of life whereas the onset of FMO3 expression does not occur in some individuals until 1-2 y. Thus, in contrast to CYP3A, overall FMO expression is low to nondetectable in the neonatal period. Given the differential ability of FMO1 and FMO3 to catalyze the oxidation of trimethylamine to its $\mathrm{N}$-oxide (15), this observation likely explains the observation of trimethylaminuria in a 2-mo- and a 4-y-old patient that resolved with no intervention by 4 mo and $5 \mathrm{y}$, respectively (51). Finally, C/EBP $\alpha$ (CCAAT/enhancerbinding protein alpha) and DBP (D-element-binding protein) transcription factors have been implicated as controlling factors for the temporal CYP3A switch (52). Although a role for these factors in regulating the onset of $F M O 3$ expression has not been examined, HNF $1 \alpha$ and HNF $4 \alpha$ have been shown to be the major transcription factors controlling the expression of rabbit and human $F M O 1$, whereas $\mathrm{C} / \mathrm{EBP} \alpha$ does not appear to have a significant role (53). Taken together, these observations suggest very different mechanisms controlling the CYP3A and FMO temporal switches in the human.

Several studies have implicated a role for sex steroids and/or gender in regulating FMO expression in animal models. Testosterone has been shown to suppress FMO1 and FMO3 hepatic activity in the mouse, but stimulatory effects of $17 \beta$ estradiol were not observed $(41,44)$. These modulating effects of testosterone largely account for the hepatic FMO1 and FMO3 gender differences in this species. In contrast, $17 \beta-$ estradiol has been shown to suppress FMO activity in rat hepatocytes (45), however, no gender-dependent FMO1 or FMO3 expression was observed in the livers of intact animals (12). Both progesterone and glucocorticoids have been implicated in stimulating FMO2 expression in the rabbit lung and kidney $(54,43)$, perhaps explaining some of the noted gender differences in FMO expression observed in this species (22). In marked contrast to results for each of these animal models, there is little or no evidence for steroid-regulation of human hepatic FMO expression (24). Consistent with this observation, neither the repression of FMO1 at birth, the onset of FMO3 expression at 1-2 y, or the increase in $\mathrm{FMO} 3$ expression at puberty were correlated with gender in the current study.

Significant interindividual variability in the expression of human FMO has been reported. Using monospecific antibodies, Overby et al. (47) reported a 10-fold variation in hepatic FMO3-specific content which, despite a limited sample size ( $n$ $=5$ ), agrees favorably with several reports on activity measurements using specific substrates and preparations of human hepatic microsomes (55-57). A similar earlier study on fetal liver, also limited to a sample size of five, reported a 2-fold variation in FMO1 specific content (25). Most importantly, other than restricting their studies to fetal or adult samples, these reports failed to control for changes in FMO1 and FMO3 expression as a function of age. Based on the data reported herein, this is a major confounding factor in interpreting these earlier reports. In the current study, the much larger sample size allowed for stratification according to major age brackets between which significant differences in FMO expression were 
observed. In general, the results corroborate the earlier reports, providing confidence in the conclusion of considerable interindividual variability in both FMO1 and FMO3 expression. Within each age bracket and excluding samples in which no immunoreactive FMO was detectable as well as outliers, specific content varied from 2- to 20-fold. Dietary indoles are the only environmental substances known to modulate FMO expression, suppressing FMO3 levels 2- to 3-fold (58, 59). However, it is unknown whether indoles are able to similarly modulate FMO1 and further, it is unlikely that such dietary components would be responsible for the variability among the fetal and neonatal samples. Interindividual variation might also be explained by genetic differences. Although no polymorphisms have been reported for human FMO1, several genetic variants have been reported for human FMO3 (26-28, 60-65). However, variants representing nonsense mutations that would be expected to affect FMO3 specific content are rare $(62,61)$. Thus, the variation observed in the present study most likely represents variation in factors controlling FMOI and FMO3 expression and/or regulatory polymorphisms that remain to be elucidated.

In summary, this study describes the developmental expression pattern for human hepatic FMO1 and FMO3. The temporal switch between these two enzymes has been defined. Further, it is clear from these data that the variability in the switch is almost exclusively accounted for by variability in the onset of FMO3 expression. Considerable interindividual variation in FMO1 and FMO3 expression within each of the defined age brackets also has been confirmed, most likely because of variation in factors regulating expression. The relatively high levels of FMO1 expression observed throughout prenatal development and in particular during the embryonic periods cause one to question whether or not this enzyme might be playing some developmentally important function. However, a role for FMO, and, in particular, FMO1, in the metabolism of endogenous substances remains elusive. FMO1 has been implicated in the oxidation of methionine, cysteamine, and numerous cysteine-S-conjugates (3), but the significance of these pathways to development, if any, is not apparent. In contrast, the FMO are recognized as being important for the metabolic disposition of a wide variety of therapeutics and environmental toxicants. It is clear that isoform switching, changes in expression as a function of age, and interindividual variability in expression will have a significant impact on therapeutic efficacy and toxicant susceptibility. This particularly will be true for drugs with narrow therapeutic indices and toxicants that require metabolism for either detoxification and/or bioactivation. Although our knowledge concerning the molecular mechanisms controlling FMO expression remains deficient, the data reported in this study offer significant insight into the developmental expression pattern for both FMO1 and FMO3 that will be important for the elucidation of these regulatory mechanisms.

Acknowledgments. The authors thank D. Gail McCarver, M.D., Department of Pediatrics, Division of Neonatology, Medical College of Wisconsin, for assistance in evaluating disease processes that might have resulted in damage to the available liver samples.

\section{REFERENCES}

1. Ziegler DM 1993 Recent studies on the structure and function of multisubstrate flavin-containing monooxygenases. Annu Rev Pharmacol Toxicol 33:179-199

2. Cashman JR 1995 Structural and catalytic properties of the mammalian flavincontaining monooxygenase. Chem Res Toxicol 8:165-181

3. Elfarra AA 1995 Potential role of the flavin-containing monooxygenases in the metabolism of endogenous compounds. Chem Biol Interact 96:47-55

4. Rettie AE, Fisher MB 1999 Transformation enzymes: oxidative; non-P450. In: Woolf TF (ed) Handbook of Drug Metabolism. Marcel-Dekker, New York, pp 131-145

5. Bhamre S, Bhagwat SV, Shankar SK, Boyd MR, Ravindranath V 1995 Flavincontaining monooxygenase mediated metabolism of psychoactive drugs by human brain microsomes. Brain Res 672:276-280

6. Clement B, Lustig KL, Ziegler DM 1993 Oxidation of desmethylpromethazine catalyzed by pig liver flavin-containing monooxygenase: Number and nature of metabolites. Drug Metab Dispos 21:24-29

7. Cashman JR, Celestial JR, Leach A, Newdoll J, Park SB 1993 Tertiary amines related to brompheniramine: preferred conformations for N-oxygenation by the hog liver flavin-containing monooxygenase. Pharm Res 10:1097-1105

8. Cashman JR, Park SB, Yang Z-C, Washington CB, Gomez DY, Giacomini KM, Brett CM 1993 Chemical, enzymatic, and human enantioselective $S$-oxygenation of cimetidine. Drug Metab Dispos 21:587-597

9. Chung W-G, Park C-S, Roh H-K, Lee W-K, Cha Y-N 2000 Oxidation of ranitidine by isozymes of flavin-containing monooxygenase and cytochrome P450. Jpn J Pharmacol 84:213-220

10. Mushiroda T, Douya R, Takahara E, Nagata O 2000 The involvement of flavincontaining monooxygenase but not CYP3A4 in metabolism of itopride hydrochloride, a gastroprokinetic agent: comparison with cisapride and mosapride citrate. Drug Metab Dispos 28:1231-1237

11. Hajjar NP, Hodgson E 1980 Flavin adenine dinucleotide-dependent monooxygenase: its role in the sulfoxidation of pesticides in mammals. Science 209:1134-1136

12. Frederick CB, Mays JB, Ziegler DM, Guengerich FP, Kadlubar FF 1982 Cytochrome $\mathrm{P}-450$ - and flavin-containing monooxygenase-catalyzed formation of the carcinogen N-hydroxy-2-aminofluorene and its covalent binding to nuclear DNA. Cancer Res 42:2671-2677

13. Berkman CE, Park SB, Wrighton SA, Cashman JR 1995 In vitro-in vivo correlations of human (S)-nicotine metabolism. Biochem Pharmacol 50:565-570

14. Cashman JR, Ziegler DM 1986 Contribution of N-oxygenation to the metabolism of MPTP (1-methyl-4-phenyl-1,2,3,6-tetrahydropyridine) by various liver preparations. Mol Pharmacol 29:163-167

15. Lang DH, Yeung CK, Peter RM, Ibarra C, Gasser R, Itagaki K, Philpot RM, Rettie AE 1998 Isoform specificity of trimethylamine N-oxygenation by human flavincontaining monooxygenase (FMO) and P450 enzymes: Selective catalysis by FMO3. Biochem Pharmacol 56:1005-1012

16. Ziegler DM 1980 Microsomal flavin-containing monooxygenase: Oxygenation of nucleophilic and sulfur compounds. In: Jakoby WB (ed) Enzymatic Basis of Detoxication. Academic Press, New York, pp 201-227

17. Shephard EA, Dolphin CT, Fox MF, Povey S, Smith R, Phillips IR 1993 Localization of genes encoding three distinct flavin-containing monooxygenases to human chromosome 1q. Genomics 16:85-89

18. McCombie RR, Dolphin CT, Povey S, Phillips IR, Shephard EA 1996 Localization of human flavin-containing monooxygenase genes FMO2 and FMO5 to chromosome 1q. Genomics 34:426-429

19. Poulsen LL, Ziegler DM 1995 Multisubstrate flavin-containing monooxygenases: applications of mechanism to specificity. Chem Biol Interact 96:57-73

20. Tynes RE, Philpot RM 1987 Tissue- and species-dependent expression of multiple forms of mammalian microsomal flavin-containing monooxygenase. Mol Pharmacol 31:569-574

21. Overby L, Nishio SJ, Lawton MP, Plopper CG, Philpot RM 1992 Cellular localization of flavin-containing monooxygenase in rabbit lung. Exp Lung Res 18:131-144

22. Shehin-Johnson SE, Williams DE, Larsen-Su S, Stresser DM, Hines RN 1995 Tissue-specific expression of flavin-containing monooxygenase (FMO) forms 1 and 2 in the rabbit. J Pharmacol Exp Ther 272:1293-1299

23. Dolphin CT, Cullingford TE, Shephard EA, Smith RL, Phillips IR 1996 Differential developmental and tissue-specific regulation of expression of the genes encoding three members of the flavin-containing monooxygenase family of man, FMO1, FM03 and FM04. Eur J Biochem 235:683-689

24. Cherrington NJ, Cao Y, Cherrington JW, Rose RL, Hodgson E 1998 Physiological factors affecting protein expression of flavin-containing monooxygenases 1,3 , and 5 . Xenobiotica 28:673-682

25. Yeung CK, Lang DH, Thummel KE, Rettie AE 2000 Immunoquantitation of FMO1 in human liver, kidney, and intestine. Drug Metab Dispos 28:1107-1111

26. Cashman JR, Bi YA, Lin J, Youil R, Knight M, Forrest S, Treacy E 1997 Human flavin-containing monooxygenase form 3: cDNA expression of the enzymes containing amino acid substitutions observed in individuals with trimethylaminuria. Chem Res Toxicol 10:837-841

27. Dolphin CT, Janmohamed A, Smith RL, Shephard EA, Phillips IR 1997 A Missense mutation in flavin-containing mono-oxygenase 3 gene, FMO3, underlies fish-odour syndrome. Nat Genet 17:491-494

28. Treacy EP, Akerman BR, Chow LML, Youil R, Bibeau C, Lin J, Bruce AG, Knight M, Danks DM, Cashman JR, Forrest SM 1998 Mutations of the flavin-containing 
monooxygenase gene (FMO3) cause trimethylaminuria, a defect in detoxication. Hum Mol Genet 7:839-845

29. Whetstine JR, Yueh M-F, Hopp KA, McCarver DG, Williams DE, Park C-S, Kang Y-N, Cha Y-N, Dolphin CT, Shephard EA, Phillips IR, Hines RN 2000 Ethnic differences in human flavin-containing monooxygenase 2 (FMO2) polymorphisms: detection of expressed protein in African-Americans. Toxicol Appl Pharmacol $168: 216-224$

30. van Ooij C, Snyder RC, Paeper BW, Duester G 1992 Temporal expression of the human alcohol dehydrogenase gene family during liver development correlates with differential promoter activation by hepatocyte nuclear factor 1, CCAAT/enhancerbinding protein $\alpha$, liver activator protein, and D-element-binding protein. Mol Cell Biol 12:3023-3031

31. van Lieshout EM, Knapen MF, Lange WP, Steegers EA, Peters WH 1998 Localization of glutathione S-transferases alpha and pi in human embryonic tissues at 8 weeks gestational age. Hum Reprod 13:1380-1386

32. Hines RN, Luo Z, Cresteil T, Ding X, Prough RA, Fitzpatrick JL, Ripp SL, Falkner KC, Ge N-L, Levine A, Elferink CJ 2001 Molecular regulation of gene encoding xenobiotic metabolizing enzymes: mechanisms involving endogenous factors. Drug Metab Dispos 29:623-633

33. de Wildt SN, Kearns GL, Leeder JS, van den Anker JN 1999 Glucuronidation in humans: pharmacogenetic and developmental aspects. Clin Pharmacokinet 36:439452

34. Lomri N, Gu Q, Cashman JR 1992 Molecular cloning of the flavin-containing monooxygenase (form II) cDNA from adult human liver. Proc Natl Acad Sci U S A 89:1685-1689

35. Sadeque AJM, Eddy AC, Meier GP, Rettie AE 1992 Stereoselective sulfoxidation by human flavin-containing monooxygenase: Evidence for catalytic diversity between hepatic, renal, and fetal forms. Drug Metab Dispos 20:832-839

36. Pearce RE, McIntyre CJ, Madan A, Sanzgiri U, Draper AJ, Bullock PL, Cook DC, Burton LA, Latham J, Nevins C, Parkinson A 1996 Effects of freezing, thawing, and storing human liver microsomes on cytochrome P450 activity. Arch Biochem Biophys 331:145-169

37. Smith PK, Krohn RI, Hermanson GT, Mallia AK, Gartner FH, Provenzano MD, Fujimoto EK, Goeke NM, Olson BJ, Klenk DC 1985 Measurement of protein using bicinchoninic acid. Anal Biochem 150:76-85

38. Laemmli UK 1970 Cleavage of structural proteins during the assembly of the head of the bacteriophage T4. Nature 227:680-685

39. Towbin HH, Staehelin T, Gordon J 1979 Electrophoretic transfer of proteins from polyacrylamide gels to nitrocellulose sheets: Procedure and some applications. Proc Natl Acad Sci U S A 76:4350-4354

40. Sadeque AJM, Thummel KE, Rettie AE 1993 Purification of macaque liver flavincontaining monooxygenase: a form of the enzyme related immunochemically to an isozyme expressed selectively in adult human liver. Biochim Biophys Acta Protein Struct Mol Enzymol 1162:127-134

41. Duffel MW, Graham JM, Ziegler DM 1981 Changes in dimethylaniline N-oxidase activity of mouse liver and kidney induced by steroid sex hormones. Mol Pharmacol 19:134-139

42. Dannan GA, Guengerich FP, Waxman DJ 1986 Hormonal regulation of rat liver microsomal enzymes. Role of gonadal steroids in programming, maintenance and suppression of delta ${ }^{4}$-steroid $5 \alpha$-reductase, flavin-containing monooxygenase, and sex-specific cytochromes P-450. J Biol Chem 261:10728-10735

43. Lee M-Y, Clark JE, Williams DE 1993 Induction of flavin-containing monooxygenase (FMO B) in rabbit lung and kidney by sex steroids and glucocorticoids. Arch Biochem Biophys 302:332-336

44. Falls JG, Ryu DY, Cao Y, Levi PE, Hodgson E 1997 Regulation of mouse liver flavin-containing monooxygenases 1 and 3 by sex steroids. Arch Biochem Biophys 342:212-223

45. Coecke S, Debast G, Phillips IR, Vercruysse A, Shephard EA, Rogiers V 1998 Hormonal regulation of microsomal flavin-containing monooxygenase activity by sex steroids and growth hormone in co-cultured adult male rat hepatocytes. Biochem Pharmacol 56:1047-1051

46. Gasser R 1996 The flavin-containing monooxygenase system. Exp Toxicol Pathol 48:467-470
47. Overby LH, Carver GC, Philpot RM 1997 Quantitation and kinetic properties of hepatic microsomal and recombinant flavin-containing monooxygenases 3 and 5 from humans. Chem Biol Interact 106:29-45

48. Larsen-Su S, Krueger SK, Yueh MF, Lee MY, Shehin SE, Hines RN, Williams DE 1999 Flavin-containing monooxygenase isoform 2: developmental expression in fetal and neonatal rabbit lung. J Biochem Mol Toxicol 13:187-193

49. Yang H-YL, Lee QP, Rettie AE, Juchau MR 1994 Functional cytochrome P4503A isoforms in human embryonic tissues: expression during organogenesis. Mol Pharmacol 46:922-928

50. Lacroix D, Sonnier M, Moncion A, Cheron G, Cresteil T 1997 Expression of CYP3A in the human liver. Evidence that the shift between CYP3A7 and CYP3A4 occurs immediately after birth. Eur J Biochem 247:625-634

51. Mayatepek E, Kohlmueller D 1998 Transient trimethylaminuria in childhood. Acta Paediatr 87:1205-1207

52. Ourlin JC, Jounaïdi Y, Maurel P, Vilarem MJ 1997 Role of the liver-enriched transcription factors $\mathrm{C} / \mathrm{EBP} \alpha$ and DBP in the expression of human CYP3A4 and CYP3A7. J Hepatol 26:54-62

53. Luo Z, Hines RN 2001 Regulation of flavin-containing monooxygenase 1 (FMO1) expression by ying yang 1 (YY1) and hepatic nuclear factors 1 (HNF1) and 4 (HNF4). Mol Pharmacol 60:1421-1430

54. Devereux TR, Fouts JR 1975 Effect of pregnancy or treatment with certain steroids on $\mathrm{N}, \mathrm{N}$-dimethylaniline demethylation and $\mathrm{N}$-oxidation by rabbit liver or lung microsomes. Drug Metab Dispos 3:254-258

55. McManus ME, Birkett DJ, Burgess WM, Stupans I, Koenig JA, Boobis AR, Davies DS, Wirth PJ, Grantham PH, Thorgeirsson SS 1986 Flavin-containing monooxygenase activity in human liver microsomes. In: Kocsis JJ, Jollow DJ, Witmer CM, Nelson JO, Snyder R (eds) Advances in Experimental Biology and Medicine. Plenum Press, New York, pp 773-779

56. Störmer E, Roots I, Brockmöller J 2000 Benzydamine $N$-oxidation as an index reaction refelcting FMO activity in human liver microsomes and impact of FMO3 polymorphisms on enzyme activity Br J Clin Pharmacol 50:553-561

57. Kang J-H, Chung W-G, Lee K-H, Park C-S, Kang J-S, Shin I-C, Roh H-K, Dong M-S, Baek H-M, Cha Y-N 2000 Phenotypes of flavin-containing monooxygenase activity determined by ranitidine $\mathrm{N}$-oxidation are positively correlated with genotypes of linked FMO3 gene mutations in a Korean populations. Pharmacogenetics 10:67-78

58. Larsen-Su S, Williams DE 1996 Dietary indole-3-carbinol inhibits FMO activity and the expression of flavin-containing monooxygenase form 1 in rat liver and intestine. Drug Metab Dispos 24:927-931

59. Cashman JR, Xiong Y, Lin J, Verhagen H, van Poppel G, Van Bladeren PJ, Larsen-Su $\mathrm{S}$, Williams DE 1999 In vitro and in vivo inhibition of human flavin-containing monooxygenase form 3 (FMO3) in the presence of dietary indoles. Biochem Pharmacol 58:1047-1055

60. Akerman BR, Forrest S, Chow L, Youil R, Knight M, Treacy EP 1999 Two novel mutations of the FMO3 gene in a proband with trimethylaminuria. Hum Mut $13: 376-379$

61. Akerman BR, Lemass H, Chow LML, Lambert DM, Greenberg C, Bibeau C, Mamer OA, Treacy EP 1999 Trimethylaminuria is caused by mutations of the FMO3 gene in a North American cohort. Mol Genet Metab 68:24-31

62. Park C-S, Chung W-G, Kang J-H, Roh H-K, Lee K-H, Cha Y-N 1999 Phenotyping of flavin-containing monooxygenase using caffeine metabolism and genotyping of FMO3 gene in a Korean population. Pharmacogenetics 9:155-164

63. Zschocke J, Kohlmueller D, Quak E, Meissner T, Hoffmann GF, Mayatepek E 1999 Mild trimethylaminuria caused by common variants in FMO3 gene. Lancet 354:834835

64. Murphy HC, Dolphin CT, Janmohamed A, Holmes HC, Michelakakis H, Shephard EA, Chalmers RA, Phillips IR, Iles RA 2000 A novel mutation in the flavincontaining monooxygenase 3 gene, FMO3, that causes fish-odour syndrome; activity of the mutant enzyme assessed by proton NMR spectroscopy. Pharmacogenetics 10:439-451

65. Dolphin CT, Janmohamed A, Smith RL, Shephard EA, Phillips IR 2000 Compound heterozygosity for missense mutations in the flavin-containing monooxygenase 3 (FMO3) gene in patients with fish-odour syndrome. Pharmacogenetics 10:799-807 